Psychological Medicine, 1992, 22, 839-842. Copyright (c) 1992 Cambridge University Press

Printed in Great Britain

\title{
EDITORIAL
}

\section{Cognitive abnormalities and schizophrenic symptoms ${ }^{1}$}

It is clearly important to construct a model of schizophrenic dysfunction which is able to integrate both its neural and perceptual/cognitive aspects. Although information-processing models appear useful as a means of linking biological and social factors relevant to the disorder, "there remains a gap between the computer terminology in which attentional theories are couched and the patients's experience of schizophrenia' (Anscombe, 1987, p. 291). There are further difficulties with this approach. First, there is no agreed model of normal cognitive functioning and, as Shallice (1988) notes "large-scale information theories are very loosely characterized; adding a connection, a constraint, or another subsystem to a model is unfortunately only too easy' (p. 321). Secondly, it is difficult to relate such research to biological models. Thirdly, schizophrenics perform poorly on most tasks; to rule out an explanation in terms of a 'generalized deficit', one requires the demonstration of a differential pattern of performance uncontaminated by task difficulty, or, preferably, schizophrenics' superior performance.

In considering schizophrenics' disturbances of perception and cognition, a number of theoretical models have been drawn upon, and these often differ considerably in their assumptions concerning the nature of normal information processing. It is clearly hazardous to attempt to interpret studies in a different framework from those in which they were designed. However, I have argued (Hemsley, 1987) that, in part, models such as those of Broadbent (1971), Posner (1982) and Shiffrin \& Schneider (1977), illustrate the way in which the spatial and temporal regularities of past experience influence the processing and, more speculatively, awareness, of current sensory input. A review of research on schizophrenics' cognitive abnormalities employing such models suggests that 'it is a weakening of the influence of stored memories of regularities of previous input on current perception which is basic to the schizophrenic condition' (Hemsley, 1987, p. 182). It is not claimed that the 'memories of past regularities' are not stored, nor that they are inaccessible. Rather the suggestion is that the rapid and automatic assessment of the significance, or lack of significance, of aspects of sensory input (and their implications for action) is impaired. The awareness of redundant information would therefore be affected. It should hence be possible to construct tasks on which schizophrenics perform better than normals due to the latter forming expectancies which are inappropriate to the new context in which a stimulus is presented.

A disturbance of this kind is intriguingly reminiscent of earlier descriptions of the ways in which schizophrenics' perceptions and/or thinking are disturbed. As Cutting (1989) points out, Matussek (1952) and Conrad (1958) were among the first to argue that the early stage of schizophrenia could be explained in terms of a breakdown of Gestalt perception, and that such a disturbance could form the basis of delusional perception. Matussek (1952) describes a patient who was aware of 'a lack of continuity of his perceptions both in space and over time' (cf. failure to make use of spatial and temporal redundancy): 'He saw the environment only in fragments. There was no appreciation of the whole. He saw only details against a meaningless background' (p. 92). Arieti (1966) later used the term perceptual and apperceptual fragmentation for such phenomena. In similar vein, Shakow's experimental work had led him to the conclusion that a schizophrenic 'can't see the wood for the trees.... and examines each tree with meticulous care' (Shakow, 1950, p. 386).

Recent research relevant to Hemsley's (1987) formulation has drawn on animal learning theory in devising experimental paradigms. This has become increasingly 'cognitive' and the setting up of a viable animal model for schizophrenia no longer seems an impossibility. Two behaviourial

' Address for correspondence: Dr David R. Hemsley, Department of Psychology, Institute of Psychology, De Crespigny Park, Denmark Hill, London SES 8AF. 
phenomena, Latent Inhibition (LI) (Lubow et al. 1982) and Kamin's (1969) blocking effect, can be regarded as instances of the 'influence of stored memories of regularities of previous input on current perception'. Latent inhibition involves a reduction in the deployment of attention to a predictable, redundant stimulus; the regularity operating is that the stimulus has no consequence. In animals it is disrupted if amphetamine is administered, and this effect can be reversed with neuroleptics (Solomon et al. 1981). Interestingly, a similar effect results from damage to the hippocampal formation (Kaye \& Pearce, 1987). Lubow et al. (1982) write 'output is controlled, not like in the intact animal by the integration of previous stored inputs and the prevailing situational conditions but only by the latter' (p. 102). Clearly, this is similar to the suggestion that schizophrenics fail to make use of the redundancy and patterning of sensory input to reduce information-processing demands and the prediction is therefore of disrupted LI in acute schizophrenia. This has been demonstrated by Baruch et al. (1988); by continuing to attend to the 'redundant' stimulus, acute schizophrenics performed better than normals. Similar results were found for Kamin's (1969) blocking effect (Jones et al. 1991). Again, in animals, the blocking effect is abolished by amphetamine (Crider et al. 1982) and by damage to the hippocampus (Solomon, 1977).

It is important to note that LI does not simply represent a form of habituation, since it is disrupted by a change in context, whereas habituation is not. In schizophrenia, a key disturbance may be the failure to relate specific associations to the context in which they occur. Once again Matussek's (1952) observations are relevant. He wrote 'When the perceptual context is disturbed, individual objects acquire different properties from those which they have when the normal context prevails' (p. 94), and he suggests that the extent to which context is loosened crucially determines the severity of the disorder. The issue of severity of underlying disturbance may be crucial to our understanding of the distinction between positive and negative symptomatology. At present it is unclear whether this represents: $(a)$ two distinct disorders; $(b)$ differing severity of the same disorder; $(c)$ individual differences in reaction to the same disorder; $(d)$ different stages of the same disorder, or a combination of $(b),(c)$ and $(d)$.

Relevant to $(c)$ is Strauss' (1987) argument that certain aspects of schizophrenic functioning may reflect the action of control mechanisms which 'involve conscious and unconscious psychological processes that focus on regulating the amount of demand faced to fit the adaptive capacity available' (p. 85). Such control processes were seen (Hemsley, 1977) as relevant to negative symptomatology, the latter representing, in part, adaptive strategies to minimize the effects of the cognitive impairment. One may also speculate that the search for meaning in altered experiences diminishes over time, as actions based on these prove ineffective or counter productive. As Anscombe (1987) puts it, "less and less the subject forms his own impressions, and more and more he is impinged upon by his environment' (p. 254). A more drastic weakening of the influence of stored regularities on current perception might result in a level of disorganization such as to render difficult any goal-directed activities.

Abnormal perceptual experiences have been accorded a central role in the formation of delusions and my model (Hemsley, 1987) followed Maher (e.g. 1974, 1988) in viewing delusions as essentially a product of normal reasoning. This emphasis is also prominent in Matussek's (1952) writing. Anscombe (1987) has extended it to suggest that certain of the patient's thoughts may be imbued with a significance that is out of proportion to their real importance, simply because they happen to capture the attentional focus. He goes on to argue that both internally and externally generated material is 'not placed in the context of background knowledge' (p. 252). However, a failure to make use of 'background knowledge' raises the possibility of an abnormal reasoning style in deluded subjects in addition to well-established perceptual disturbances.

A problem which is encountered in exploring the reasoning style of deluded subjects is in setting a standard for 'correct' or 'normal' reasoning. Fischoff \& Beyth-Marom (1983) suggest that Bayesian inference provides a general framework for evaluating beliefs in the normal population, and it may be used to describe a person's consistency with, or departure from the model. Hemsley \& Garety (1986) extended this approach to the inferences of deluded subjects. Employing a 
probability inference task, two studies have demonstrated that deluded subjects require less information before reaching a decision (Huq et al. 1988; Garety et al. 1991). The second of these also indicated that after certainty is reached, deluded subjects are more likely to make a dramatic change in probability estimate following an item of disconfirmatory information. This is consistent with those models of schizophrenia which emphasize the greater influence of immediate environmental stimuli compared with the effects of prior learning (Salzinger, 1984; Hemsley, 1987).

It has frequently been argued (e.g. Weinberger et al. 1983) that pathology of the limbic system is associated with schizophrenia. In particular the hippocampus has been discussed as a possible region of the brain that might be affected. Although neuropathological studies have provided some support for this view, the findings are far from straightforward and many other brain regions have been implicated. However, the possible functions of the hippocampus appear very relevant to my (Hemsley, 1987) model. Olton et al. (1986) have suggested that 'the hippocampus may be the brain structure that allows each of the various components of a place and an event to be linked together and compared with other places and events'. In a related formulation Gray (1982) has argued for the role of the hippocampus in the comparison of actual and expected stimuli. A defect in this system could be related to a weakening of the effect of past regularities on current perception. This view has been elaborated by Schmajuk (1987) who argues for the utility of the hippocampally lesioned animal as a model for schizophrenia. Both latent inhibition and 'blocking' are disrupted by damage to the hippocampal formation. A recent model (Gray et al. 1991 $a, b$ ) has attempted to link dopaminergic activity with temporal lobe pathology, and to relate both to the disturbances of information processing considered to underlie schizophrenic symptoms. Anatomically, the model emphasizes the projections from the septo-hippocampal system, via the subiculum, to the nucleus accumbens, and their interaction with the ascending dopaminergic projection to the accumbens. Psychologically the model emphasizes a disturbance in the normal integration of stored memories of past regularities of perceptual input with ongoing motor programmes and the control of current perception. Clearly psychological and biological models of schizophrenic symptomatology are converging in intriguing ways.

DAVID R. HEMSLEY

\section{REFERENCES}

Anscombe, R. (1987). The disorder of consciousness in schizophrenia. Schizophrenia Bullerin 11, 241-260.

Ariti, S. (1966). Schizophrenic cognition. In Psychopathology of Schizophrenia (ed. P. H. Hoch and T. Zubin), pp. 37-48. Grune and Stration: New York.

Baruch, I., Hemsley, D. R. \& Gray, J. A. (1988). Differential performance of acute and chronic schizophrenics in a latent inhibition task. Journal of Nervous and Mental Disease 176, 598606.

Broadbent, D. E. (1971). Decision and Stress. Academic Press: London.

Conrad, K. (1958). Die Beginnende Schizophrenie. G. Thieme: Stuttgart.

Crider, A., Solomon, P R. \& McMahon, M. A. (1982). Attention in the rat following chronic de-amphetamine administration: relationship to schizophrenic attention disorder. Biological Psychiatry 17, 351361.

Cutting, J. (1989). Gestalt theory and psychiatry discussion paper. Journal of the Royal Society of Medicine 82, 429431.

Fischoff, B. \& Beyth-Marom, R. (1983). Hypothesis evaluation from Bayesian perspective. Psychological Review 90, 239-260.

Garety, P. A., Hemsley, D. R. \& Wessely, S. (1991). Reasoning in deluded schizophrenic and paranoid patients. Journal of Nervous and Mental Disease 179, 194201.

Gray, J. A. (1982). The Nituropsychology of Anxiety. Oxford University Press: Oxford.

Gray, J. A., Feldman, J., Rawling, J. N. P., Hemsley, D. R. \& Smith,
A. D. $(1991 a)$. The neuropsychology of schizophrenia. Behavioural and Brain Sciences 14, 1-20.

Gray, J. A., Hemsley, D. R., Gray, N., Feldon, J. \& Rawlins, J. N. P. $(1991 b)$. Schiz Bits: Misses, mysteries and hits. Behavioural and Brain Sciences 14, 56-84.

Hemsley, D. R. (1977). What have cognitive deficits to do with schizophrenic symptoms? British Journal of Psychialry 130, 167-173.

Hemsley, D. R. (1987). An experimental psychological model for schizophrenia. In Search for the Causes of Schizophrenia (ed. H. Hafner, W. F. Gattaz and W. Janzarik), pp. 179-188. Springer: Heidelberg.

Hemsley, D. R. \& Garety, PA. (1986). The formation and maintenance of delusions: Bayesian analysis. British Journal of Psychiatry 149, 51-56.

Huq, S. F., Garety, P. A. \& Hemsley, D. R. (1988). Probabilistic judgements in deluded and non-deluded subjects. Quarterly Journal of Experimental Psychology' 40A, 801-812.

Jones, S., Gray, J. A. \& Hemsley, D. R. (1991). Kaminblocking effect and incidental learning in acute and chronic schizophrenia. (Submitted for publication.)

Kamin, L. J. (1969). Predictability, surprise, attention and conditioning. In Punishment and Aversive Behaviour (ed. B. A. Campbell and R. M. Church), pp. 279-296. Appleton Century Crofts: New York

Kaye, H. \& Pearce, J. M. (1987). Hippocampal lesions eliminate latent inhibition and the decline of the orienting response in rats. Quarterly Journal of Experimental Psychology 39B, 107. 125.

Lubow, R. E., Weiner, I. \& Feldon, J. (1982). An animal model of attention. In Behavioural Models and the Analysis of Drug Action 
(M. Y. Spiegelstein and A. Levy), pp. 89-107. Elsevier: Amsterdam.

Maher, B. A. (1974). Delusional thinking and perceptual disorder. Journal of Individual Psychology 30, 98-113.

Maher, B. A. (1988). Anomalous experience and delusional thinking: the logic of explanations. In Delusional Beliefs (ed. T. F. Oltmann and B. A. Maher) pp. 15-33. Wiley: New York.

Matussek, P. (1952). Studies in delusional perception. Psychiatrie und Zeitschrift Neurologie 189, 279-318.

Olton, D. S., Wible, C. G. \& Shapiro, M. L. (1986). Mnemonic theories of hippocampal function. Behavioural Neuroscience 100, 852-855.

Posner, M. (1982). Cumulative development of attentional theory. American Psychologist 37, 168-179.

Salzinger, K. (1984). The immediacy hypothesis in a theory of schizophrenia. In Theories of Schizophrenia and Psychosis (ed. W. D. Spaulding and J. K. Cole), pp. 231-282. University of Nebraska Press: Lincoln and London.

Schmajuk, N. A. (1987). Animal models for schizophrenia: the hippocampally lesioned animal. Schizophrenia Bulletin 13, 317 . 327.

Shakow, D. (1950). Some psychological features of schizophrenia. In Feeling and Emotion (ed. M. L. Reyment), pp. 383-390. McGraw Hill: Newark.
Shallice, T. (1988). Information processing models of consciousness, possibilities and problems. In Consciousness in Contemporary Science (ed. A. J. Marcel and E. Bisiach), pp. 305 333. Clarendon Press: Oxford.

Shiffrin, R. M. \& Schneider, W. (1977). Controlled and automatic human information processing. II. Perceptual learning, automatic attending and a general theory. Psychological Revie'w 84, 127190.

Solomon, P. R. (1977). Role of the hippocampus in blocking and conditional inhibition of rabbits nictitating membrane response. Journal of Comparative and Physiological Psychology 91, 407417

Solomon, P. R., Crider, A., Winterman, J. W., Tuvi, A., Kamer, R. M. \& Kaplan, L. J. (1981). Disrupted latent inhibition in the rat with chronic amphetamine or haloperidol induced supersensitivity: relationship to schizophrenic attention disorder. Biological Psychiatry 16, 519-537.

Strauss, J. (1987). Processes of healing and chronicity in schizophrenia. In Search for the Causes of Schizophrenia (ed. H. Hafner, W. F. Gattaz and W. Janzarik), pp. 75 87. Springer Verlag: Heidelberg.

Weinberger, D. R., Wagner, R. I. \& Wyatt, R. J. (1983). Neuropathological studies of schizophrenia : a selective review. Schizophrenia Bulletin 9, 193212. 